Research article

\title{
The inflammatory infiltrate in the acute stage of the dextran sulphate sodium induced colitis: B cell response differs depending on the percentage of DSS used to induce it Liljana Stevceva ${ }^{* 1}$, Paul Pavli ${ }^{1}$, Alan J Husband ${ }^{2}$ and William F Doe ${ }^{1}$
}

Address: ${ }^{1}$ Division of Molecular Medicine, John Curtin School of Medical Research, Australian National University, Sydney, Australia and ${ }^{2}$ Faculty of Veterinary Science, The University of Sydney, Sydney, Australia

E-mail: Liljana Stevceva* - liljana@ hotmail.com; Paul Pavli - Paul.Pavli@act.gov.au; Alan J Husband - a.husband@vetp.usyd.edu.au; William F Doe - W.F.DOE@bham.ac.uk

*Corresponding author

Published: 10 September 200I

BMC Clinical Pathology 2001, I:3
Received: 29 May 2001

Accepted: 10 September 200 I

This article is available from: http://www.biomedcentral.com/I472-6890/I/3

(C) 200I Stevceva et al; licensee BioMed Central Ltd. Verbatim copying and redistribution of this article are permitted in any medium for any noncommercial purpose, provided this notice is preserved along with the article's original URL. For commercial use, contact info@biomedcentral.com

\begin{abstract}
Background: Experimental colitis with features similar to inflammatory bowel disease (IBD) has initially been described. A detailed analysis of inflammatory cells has not yet been described. Therefore in this study we characterized the cells involved in the acute phase of the colitis and compared those findings to what is known about human IBD.

Methods: Colitis was induced in BALB/C and C57B16 mice by ingestion of $2.5 \%$ and $5 \%$ DSS in the drinking water for 8 days. Cells were labelled by immunohistochemical staining with F4/80 and ER-MP20 for macrophages, TIB I 20 for MHC Class II presentation, and anti-CD4 and anti-CD8 antibodies. They were enumerated by using a novel method that employs video image analysis. Immunoglobulin-producing cells were enumerated by immunofluorescent staining for IgA, IgG and IgM and counting by using confocal microscopy.

Results: Inflammatory infiltrate in the acute phase of the dextran sulphate sodium (DSS) -induced colitis consists predominantly of macrophages, neutrophils and eosinophils. Neutrophils increase in numbers and crypt abscesses were also seen. Increased macrophage numbers were due to recently recruited monocytes from the peripheral circulation. It does not appear that there are any changes in $T$ cell numbers or distribution. The inflammation induced changes in immunoglobulinproducing cells with IgA-producing cells affected the most.
\end{abstract}

Conclusions: The effect on Ig-producing cells depends on the percentage of DSS used to induce colitis. In general, $2.5 \%$ DSS induces an increase and 5\% DSS a depletion of these cells.

\section{Background}

In healthy colonic tissues, human intestinal macrophages can be found in the mucosa next to the basal membrane of the epithelial layer [1]. In IBD, total numbers of macrophages are increased and subpopulations of mac- rophages, not normally present in the lamina propria of the intestine, appear $[2,3]$ indicating ongoing recruitment to the inflamed bowel $[4,5]$. Bearing in mind their function, macrophages may contribute to intestinal damage by releasing oxyradicals [6] and by secreting 
proinflammatory cytokines and other inflammatory mediators, by phagocytosing foreign antigens or invasive micro-organisms or by acting as antigen-presenting cells. Regarding $\mathrm{T}$ cells, total numbers of $\mathrm{T}$ cells are increased in tissue samples [7] while the ratio of $\mathrm{CD} 4^{+}$to $\mathrm{CD}^{+}$cells is unchanged in patients with ulcerative colitis and decreased in patients with Crohn's disease due to an increase in numbers of $\mathrm{CD} 8^{+}$cells [8].

One of the main histological findings in ulcerative colitis is the greatly increased number of plasma cells. It appears that $\mathrm{B}$ cells are undergoing proliferation and isotype switching as increased levels of $\mathrm{IgG}$-bearing lymphocytes have been found in the mucosal lesion of ulcerative colitis [9]. Isolated mononuclear cells from ulcerative colitis lesions secrete more IgG [10], an increase mainly due to the secretion of IgG1. On the other hand $\mathrm{IgG} 2$ secretion was increased from cells isolated from Crohn's disease patients $[11,12]$. These findings were confirmed by Gryboski [13] when studying serum immunoglobulin classes in children with ulcerative colitis and Crohn's disease. Levels of IgA are decreased in chronic ulcerative colitis [14], severe ulcerative colitis and Crohn's disease, but not as much in less active IBD [15] and are increased in quiescent disease [16].

Experimental colitis, similar to IBD and induced with ingestion of DSS was initially described by Okayasu et al. [17]. Our findings confirmed that the lesion consists of inflammatory infiltration and consecutive multiple mucosal ulcers [18]. The lesion was characterized by an inflammatory infiltration with monocytic cells, neutrophils and eosinophils as assessed by histopathological examination of the involved tissue. In this study, we characterized the inflammatory cells involved in the early response to DSS and compared these findings with the findings in human IBD.

\section{Materials and methods \\ Immunohistochemical staining and counting of positive cells}

Mice were sacrificed at 3, 6 and 8 days of exposure to either $2.5 \%$ or $5 \%$ DSS, the colons were removed and fixed in periodate-lysine-paraformaldehyde (PLP) for 3 hours. Tissue was then transferred to $20 \%$ sucrose for $3-4 \mathrm{~h}$ and to $7 \%$ sucrose prior to embedding. PLP-fixed tissues were embedded in OCT compound (Miles Inc. Diagnostic Division, Elkhart, USA). Serial transverse, $6 \mu$ thick sections of the colon were washed in phosphate-buffered saline (PBS) for 5 min twice to remove OCT. Non-specific $\mathrm{Fc}$ binding was blocked by incubating with goat antimouse IgG $(\mathrm{H}+\mathrm{L})$ (Caltag Immunodiagnostics, San Francisco, CA, USA) $100 \mu \mathrm{l} / 10 \mathrm{ml}$ PBS and $2 \%$ sheep serum for $30 \mathrm{~min}$. The monoclonal antibodies $\mathrm{F} 4 / 80$ (used as supernatant, 1:3 in PBS) and ER-MP 20 (BMA, Rhein- strasse, Switzerland) (1:200) were used to show macrophage infiltration and activation during the process of inflammation. TIB 120 (used as supernatant, neat) was used to assess MHC class II expressing cells. Anti-CD4 (Pharmingen, San Diego, CA, USA) and anti-CD8 antibodies (Pharmingen, San Diego, CA, USA) (1:100) were used to show $\mathrm{T}$ cell infiltration as primary antibodies and applied after the blocking step. Omission of the primary or secondary antibody or appropriate isotype controls (unrelated antibodies of IgA isotype and IgG2b isotype standard, Pharmingen, San Diego, CA, USA) was used as negative controls. Spleen sections were used as positive controls. Following $60 \mathrm{~min}$ incubation at room temperature, slides were rinsed in PBS for 5 min twice, dehydrated in ethanol and endogenous peroxidase activity was blocked using $0.1 \%$ hydrogen peroxide in methanol for $10 \mathrm{~min}$. Slides were rehydrated in ethanol, washed for 5 min twice in PBS then biotinylated sheep anti-rat antibody (Amersham International, Buckinghamshire, UK) (1:200 in PBS) was applied as a secondary antibody for 30 min followed by washing for $5 \mathrm{~min}$ twice in PBS. The avidin-biotinylated horseradish peroxidase complex (ABC kit, Vectastain, Vector Laboratories, Inc., Burlingame, CA, USA) was used to detect the relevant antigen by incubating with $\mathrm{ABC}$ for 30 min followed by washing in PBS for $5 \mathrm{~min}$ twice. Di-aminobenzidine (Sigma Chemical CO, St Louis, USA) (DAB, 1:5 in PBS) combined with $1 \mathrm{ml}$ imidazole (10 $\mathrm{mM}$ ) and $15 \mu \mathrm{ll} 30 \%$ hydrogen peroxide was used as a substrate and was applied for $10 \mathrm{~min}$. Tissue sections were washed in water for $3 \mathrm{~min}$, counterstained using Mayer's haematoxylin and mounted using Histoclad (Clay Adams, Parsippany, NJ, USA).

The most affected parts of the tissue were chosen to do the cell counting. Positive cells were counted on the whole transverse section using the NIH 1.55 video image analysis program and were expressed as the number of positive cells per $\mathrm{mm}^{2}$ lamina propria. The width and length of the microscopic area were measured using a calibration slide and the surface area on the microscope slide was calculated in the following way:

surface area $=$ width $(180 \mu) \times$ length $(130 \mu)=23,400 \mu^{2}$

Then, the whole area was selected and measured on the screen and was $27549835264 \mu^{2}$. The relationship between the magnification and the surface areas on the screen and the slide is expressed by the following equation:

Magnification $=$ area on the screen $/$ area on the slide $=$ $27549835264 / 23400=1177.34$ or 1177

Only the lamina propria was marked and its surface area measured. Crypts and epithelial cells were not included 
in this calculation. The results of the area measurement were corrected for the magnification of the microscope and the screen by dividing them by 1177 . The number of positive cells was counted on the whole transverse section, within the area marked and expressed as positive cells per $\mathrm{mm}^{2}$ lamina propria.

\section{Assessment of DSS uptake by macrophages}

Peritoneal macrophages were isolated by injecting $10 \mathrm{ml}$ PBS supplemented with $10 \mathrm{U}$ heparin into the peritoneal cavity, massaging for several minutes and carefully withdrawing the fluid. The solution was centrifuged for $5 \mathrm{~min}$ at $1500 \mathrm{~g}$, the supernatant was removed and the cell pellet resuspended in RPMI medium for cell culture containing $10 \%$ heat inactivated fetal calf serum, $50 \mathrm{U} / \mathrm{ml}$ penicillin, $4 \mathrm{mM}$ glutamine $200 \mathrm{mM}$ and $50 \mathrm{mg} / \mathrm{ml}$ gentamycin. The procedure was repeated three times. The number of cells in the fluid was counted on a haemocytometer and the final concentration was adjusted to $2 \times$ $10^{5}$ cells $/ \mathrm{ml}$, and then cultured in chamber slides in RPMI medium. After $24 \mathrm{~h}$ the medium was replaced by $5 \%$ DSS solution in RPMI or RPMI alone. Cells were incubated for $24 \mathrm{~h}$ in $5 \% \mathrm{CO} 2: 95 \%$ air at $37^{\circ} \mathrm{C}$. The supernatant was removed and cells were stained using toluidine blue for $10 \mathrm{sec}$, washed with distilled water and the slides covered using aqueous mounting medium. Slides were also stained with anti-DSS antibody [19] (MAb 5B10, Raymond Purves Bone \& Joint Research laboratory, St. Leonards, NSW, Australia) using the avidin-biotin staining technique. Omission of primary antibody was used as negative control.

\section{Assessment of the specificity of MAb 5B IO}

Mab 5B10 has previously been shown to recognize 2,3-, 2,6-, and 4,6-disulphate ester ring substitution in pyranose-containing polysaccharides and to bind among others, dextran sulphate without having significant crossreactivity with commonly occurring sulphated polysaccharides [19]. In addition to what was known and prior to the immunostaining, we performed ELISA with our dextran sulphate to ensure that the antibody binds to our brand as well. Activated polyvinyl chloride immuno-assay plates (Dynatech, Alexandria, USA) were coated with $100 \mu \mathrm{l} /$ well of a $50 \mu \mathrm{g} / \mathrm{ml}$ aqueous solution of poly-Llysine (SigmaChemical CO, St Louis, USA) for one hour at $37^{\circ} \mathrm{C}$ and air-dried. DSS solution in PBS $(50 \mu \mathrm{g} / \mathrm{ml}, \mathrm{pH}$ 7.4) was added to each well and the plates incubated for one hour at $37^{\circ} \mathrm{C}$. Followed by three washes in PBSTween 20 (polyoxyethylene-sorbitan monolaurate, Sigma, $0.05 \% \mathrm{v} / \mathrm{v}), 1 \%$ BSA-PBS was added and the plates incubated for one hour at $37^{\circ} \mathrm{C}$, then after 5 washes in PBS-Tween 20 air dried and stored at $4^{\circ} \mathrm{C}$ until use. The antibody 5B10 (100 $\mu \mathrm{l}$ dissolved in $20 \mathrm{ml}$ PBS-Tween) was added to the precoated wells and incubated for 90 min at $37^{\circ} \mathrm{C}$. After three washes with PBS-Tween 20 buff- er, $100 \mu \mathrm{l}$ of sheep anti-mouse antibody conjugated with horseradish peroxidase (1:10 ooo, Amersham International, Buckinghamshire, UK) was added and the wells incubated at $4^{\circ} \mathrm{C}$ overnight. After three washes in PBSTween 20 buffer, $100 \mu$ l of OPD substrate ( 1 tablet of Calcibiochem o-Dihydrochloride dissolved in $5 \mathrm{ml}$ citrate buffer and filtered through a $0.2 \mu \mathrm{m}$ filter and with $2 \mu \mathrm{l}$ $\mathrm{H}_{2} \mathrm{O} 2$ ) was added to the wells. The reaction was stopped with $5 \mathrm{O} \mu \mathrm{I}_{3} \mathrm{M} \mathrm{H}_{2} \mathrm{SO}_{4}$ and the optical density read on a Dynatech plate reader 5/3 (660/490 nm).

\section{Plasma cell infiltration}

Plasma cell infiltration in the intestine was examined by staining with methyl green pyronine; immunofluorescent staining for specific immunoglobulin-containing cells was used to assess the presence of different immunoglobulins and any changes in the course of the colitis.

\section{Immunofluorescent staining and counting of positive cells}

The specimens were fixed using cold ethanol [20], embedded in paraffin and $5 \mu$ sections cut on to gelatin-coated slides. Immunoglobulin-containing cells were detected by immunofluorescence as previously described [21]. Briefly, tissues were dewaxed, rehydrated and then incubated with goat anti-mouse IgA ( $\alpha$-chain specific) (SeraLab, Crawley Down, Sussex, UK), followed by tetramethylrhodamine-isothiocyanate (TRITC)-conjugated rabbit anti-goat immunoglobulin (Atlantic Antibodies, Scarborough, ME, USA) for detection of IgAcontaining cells; fluorescein isothiocyanate (FITC) conjugated goat anti-mouse IgM ( $\mu$-chain specific) (Cappel, Durham, NC, USA) for detection of IgM-containing cells; FITC-conjugated mouse monoclonal antibody against mouse IgG ( $\gamma$-chain specific) (SeraLab); or FITC-conjugated mouse monoclonal antibody against mouse $\operatorname{IgE}(\varepsilon-$ chain specific) (SeraLab, Crawley Down, Sussex, UK). Following each 20 min incubation, excess reagent was removed and the slides rinsed in PBS. Finally slides were rinsed for $1 \mathrm{~h}$ in PBS and mounted in 90\% glycerol in PBS. The number of Ig-containing cells in the intestine were counted under a $40 \times$ objective and $10 \times$ eyepieces using a Zeiss Axioskop 20 microscope with incident light illumination. Each section of the intestine was scanned from the tips of the villi to the base of the mucosa, and cells were counted in a total of 30 such scans. The average number of cells per scan was expressed as cells per linear cm of intestine by multiplying by 30.3, a correction factor determined from the field width of $330 \mathrm{~mm}$, as previously described [22].

\section{Statistical analysis}

Data has been tested for significance using Mann-Whitney test for non-parametric data. 


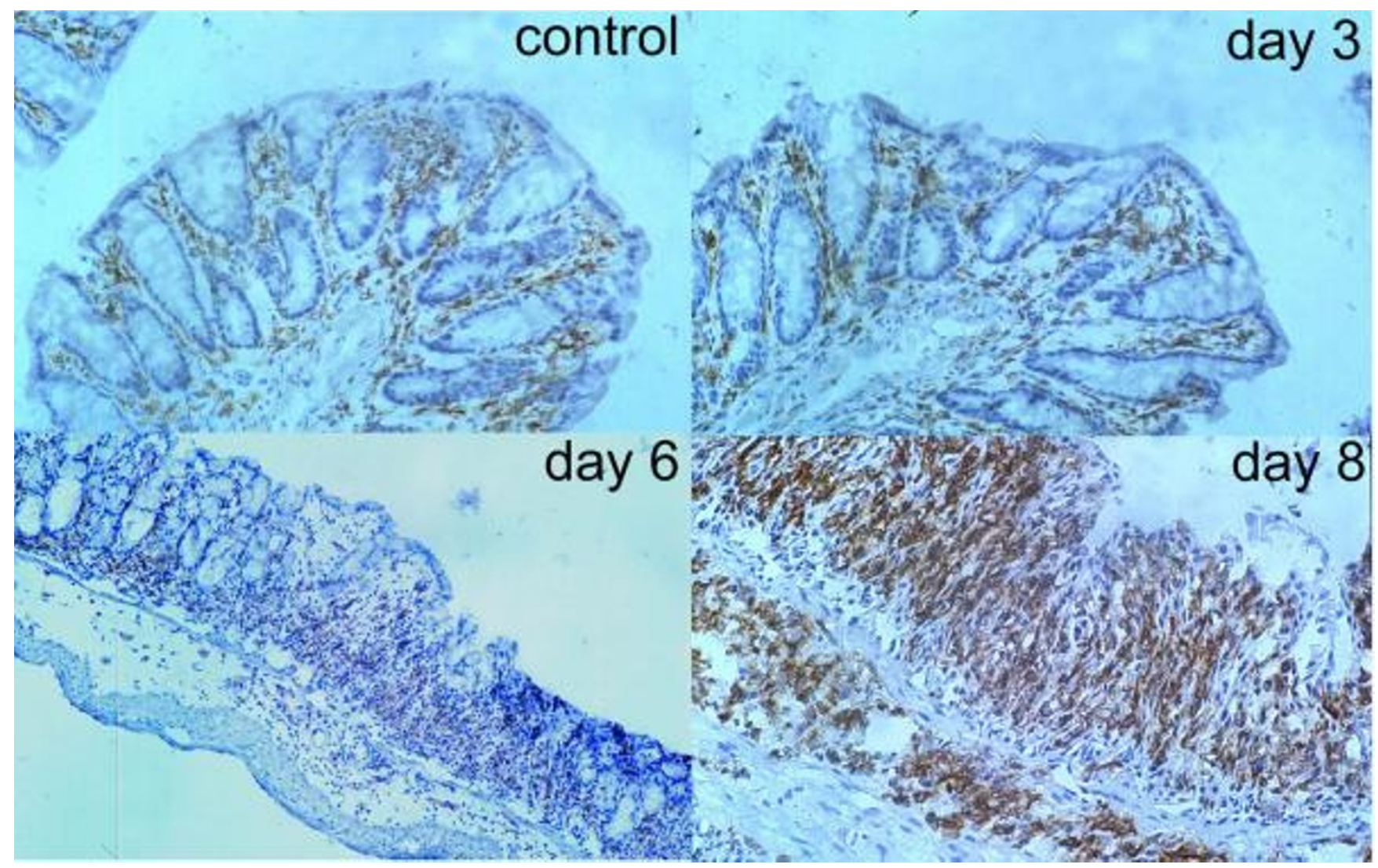

Figure I

Immunohistochemical staining for macrophages with F4/80 antibody: Macrophages in healthy colonic mucosa (control) and at day 3 of DSS ingestion are localized predominantly in the lamina propria. Positive staining for macrophages in the submucosa was initially found at day 6 and increased at day 8 of DSS ingestion. 2.5\% DSS-induced colitis. Findings from inflamed colons of $5 \%$ DSS-induced colitis were similar. Original magnification $\times 20$.

\section{Results}

The results of this study have shown a recruitment of macrophages, neutrophils and eosinophils in the inflammatory lesions as well as an increase of immunoglobulinproducing cells in the $2.5 \%$ DSS-induced colitis and a decrease in more severe, $5 \%$ DSS-induced colitis. Detailed description of the DSS colitis induced with $2.5 \%$ and $5 \%$ DSS has previously been published $[17,18]$.

\section{Macrophage numbers increase during the acute stage of} the colitis due to an increase of newly recruited monocytes In healthy colonic mouse tissues, macrophage number was low and they were localized in the subepithelial region of lamina propria mucosae. Apart from a few positive cells, the submucosa was almost devoid of $\mathrm{F} 4 / 8 \mathrm{O}^{+}$ cells. After six days of continuous feeding with DSS their numbers increased, especially at the basis of crypts and in the submucosal layer. Further increase was seen after eight days of feeding with positive cells being uniformly distributed and not focally aggregated. Numerous macrophages were also found in the submucosa (Figure 1).
Macrophage counts confirmed these findings as there was a significant difference in macrophage numbers in the inflamed colon at day eight of colitis compared to the control $(p=0.0002)$. (Figure 2). Findings were similar regardless whether $2.5 \%$ or $5 \%$ DSS was used.

ER-MP 20 is a monoclonal antibody that binds to singlechain glyco-proteins of $14 \mathrm{kD}$ [23]. The ER-MP 20 antigen is expressed at the monocyte stage of differentiation and disappears with further differentiation so it is not expressed on mature macrophages. We used the ER-MP 20 antibody to label recently recruited monocytes in the lesion and have found very few ER-MP $2 \mathrm{O}^{+}$cells in healthy tissue that were located mainly between crypts (Figure 3). After three days of feeding with DSS, ER-MP $2 \mathrm{O}^{+}$cells were found at the bases of crypts and between crypts but still in very low numbers. Numbers increased after six days of feeding: positive cells were located in the submucosa, between crypts and within the inflammatory infiltrate in the inflamed areas of the intestine and in the submucosa adjoining regions of ulceration after eight 


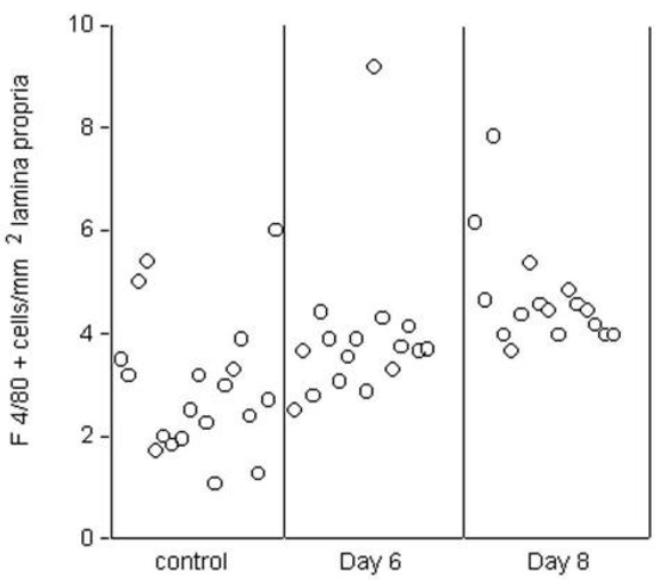

Figure 2

Numbers of macrophages (F4/80+ cells) $/ \mathrm{mm}^{2}$ lamina propria in healthy tissue and at day 6 and 8 of DSS ingestion.

days of feeding with DSS. Unfortunately, the high background prevented an accurate count of positive cells. According to these results there is recruitment of peripheral blood monocytes into the lesion.

By incubating macrophages with DSS and then using monoclonal anti-DSS antibody we were able to detect DSS within macrophages (data not shown) confirming that macrophages are able to phagocytose DSS. In addi- tion, MHC Class II expression on macrophages increased in the inflamed tissue indicating that DSS may be processed and presented as an antigen. Aggregation of MHC Class II-positive cells was seen in lymphoid follicles. Epithelial cells of the inflamed colonic mucosa also expressed MHC Class II, a finding that was not observed in healthy tissue (Figure 4).

\section{Neutrophils are recruited very early into the lesion and were found within crypts forming crypt abscesses} Staining for neutrophils was done by standard H\&E staining followed by Giemsa stain to distinguish neutrophils from eosinophils and basophils and showed an increased numbers of neutrophils from day 6 of exposure to DSS. Similarly to findings by others [17], after 6-8 days of DSS feeding they could be found within crypts forming crypt abscesses, in the epithelial layer as well as in the lumen where ulceration occurred. Specific immunohistochemical staining and counting of neutrophils was not done in this study as it has been done by others. Their results showed an early infiltration with a small number of neutrophils from day 4 that occurred before arrival of any other inflammatory cell. In this study, crypt abscesses filled with aggregated neutrophils were also seen (unpublished data, personal communication with Dr. Andrzej Wozniak). In another study, selective depletion of neutrophils by a monoclonal antibody, RP3, suppressed dextran sulphate sodium-induced colitis in rats [24]. Eosinophil numbers are also increased in this model, but lower numbers of eosinophils in IL-5 deficient mice did not ameliorate the severity of the lesions $[25]$.

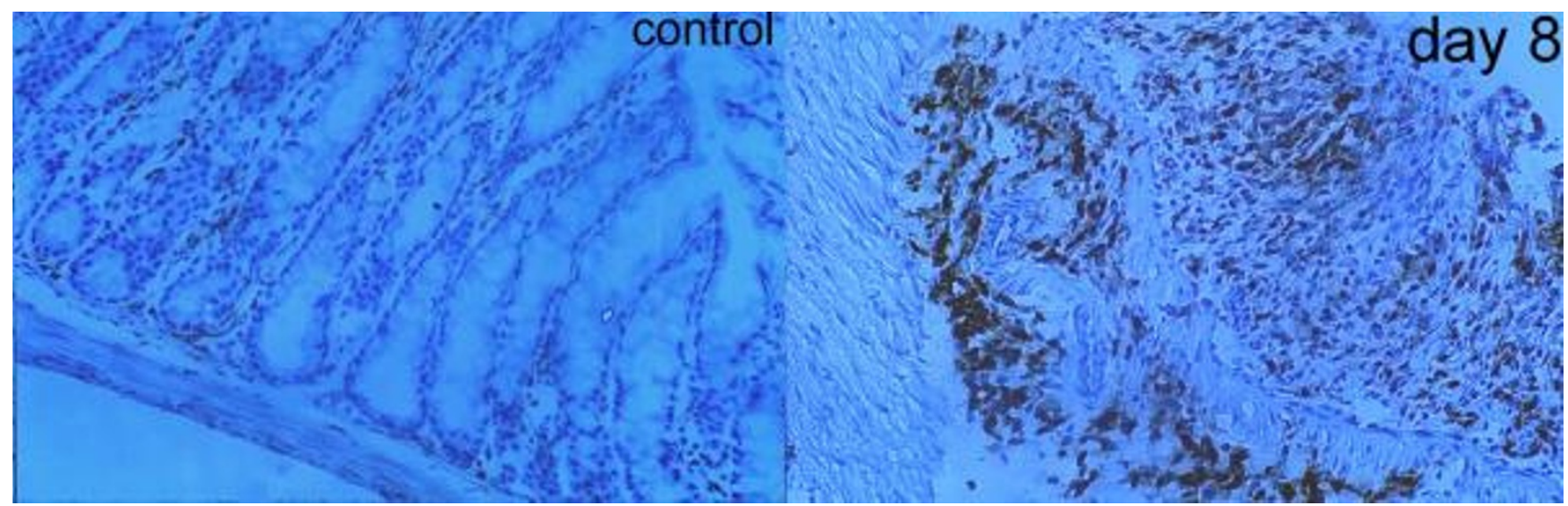

Figure 3

Recently recruited monocytes (labeled with ER-MP20 antibody) are scarce in healthy colonic tissue and greatly increased at day 8 of DSS ingestion. $2.5 \%$ DSS-induced colitis. Findings from inflamed colons of $5 \%$ DSS-induced colitis were similar. Original magnification $\times 20$. 


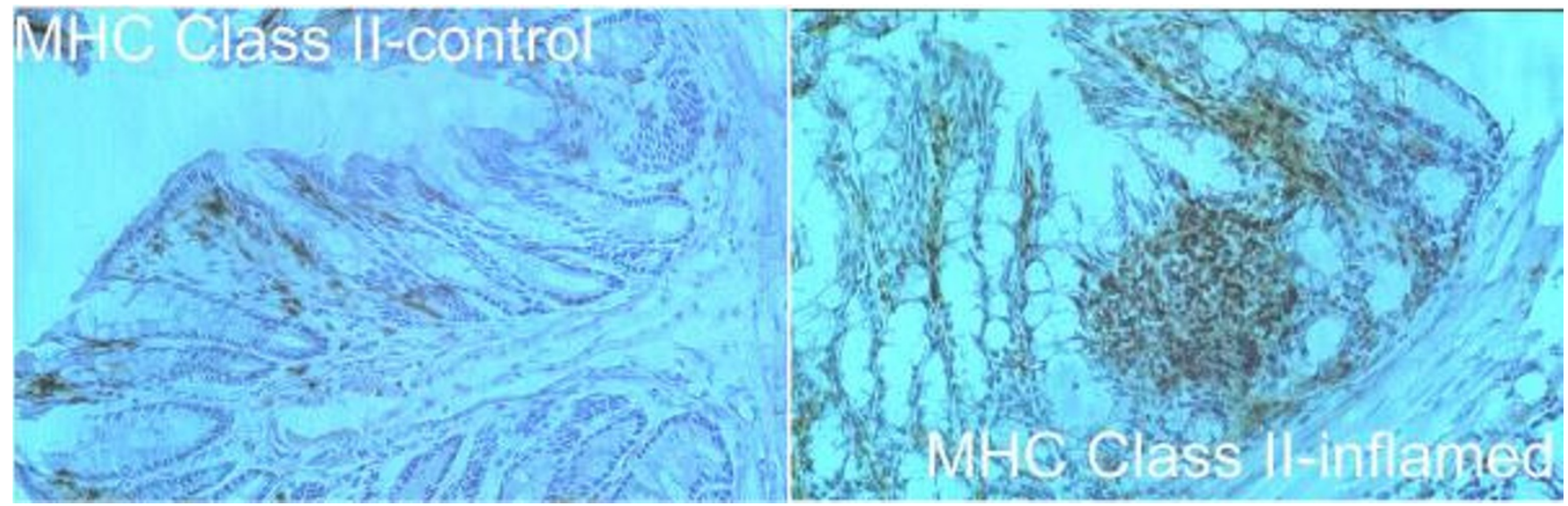

\section{Figure 4}

MHC Class II expression (labelled with TIB I20) in healthy colonic tissue (control). Epithelial cells do not express this antigen. Expression is increased in inflamed colonic tissue at day 8 of DSS ingestion. Positive cells can also be found concentrated in the lymphoid follicle and there is expression on epithelial cells. $2.5 \%$ DSS-induced colitis. Findings from inflamed colons of $5 \%$ DSSinduced colitis were similar. Original magnification $\times 20$.

\section{T cells numbers do not change during acute DSS-induced colitis}

The presence and distribution of $\mathrm{T}$ cells in the inflammatory infiltrate during DSS-induced colitis was assessed by staining with anti-CD 4 and anti-CD 8 markers.

Very few cells were $\mathrm{CD}^{+}$positive in the uninflamed colon; they were situated in the lamina propria or within the epithelial layer. Even though numbers of $\mathrm{CD}_{4}^{+}$cells were higher than the numbers of $\mathrm{CD}^{+}$cells, both, $\mathrm{CD} 4+$ and CD8+ T cells numbers did not increase during the course of the colitis (Figure 5), indicating that these cells may not be playing an important role in the acute DSSinduced colitis.

\section{Immunoglobulin A-producing cells numbers are different in} the $\mathbf{2 . 5 \%}$ DSS- than in $5 \%$ DSS-induced colitis

An increase in plasma cell numbers in the inflammatory infiltrate of the $2.5 \%$ DSS-induced colitis was first demonstrated by methyl green pyronine staining. Further evidence for changes in immunoglobulin production and distribution was obtained by using immunofluorescent staining for immunoglobulin classes.

Total numbers of immunoglobulin-containing cells (IgG, $\operatorname{Ig} \mathrm{A}, \operatorname{Ig} \mathrm{M}$ and $\operatorname{IgE})(\operatorname{IgE}+$ cells were not detected in any sample) were decreased in specimens from mice in which colitis was induced by ingestion of $5 \%$ DSS and significantly increased in specimens from the $2.5 \%$ DSSinduced colitis (Fig. 6).

Many of the changes seen in the total immunoglobulinproducing cell population were due to changes in immunoglobulin A production. In the healthy mouse colon,

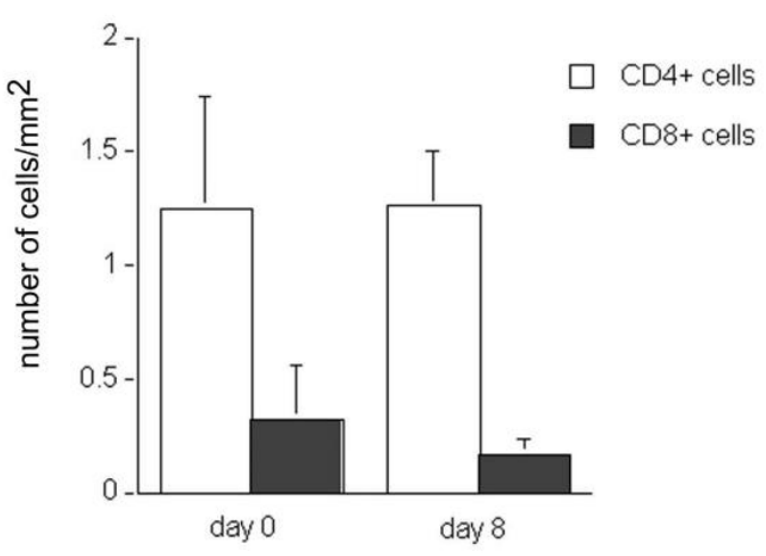

Figure 5

Numbers of CD4+ and CD8+ cells in healthy colonic lamina propria and in the inflamed colonic tissue at day 8 of $2.5 \%$ DSS ingestion. Findings from inflamed colons of $5 \%$ DSSinduced colitis were similar.

IgA-producing cells were the predominant immunoglobulin-producing cells of the colon. These cells were found in the lamina propria of the mucosa, at the basis of crypts and directly below epithelial cells. Submucosa was devoid of IgA-producing cells. IgA could also be detected within the epithelial cells especially on the luminal side. Numbers of immunoglobulin A-producing cells significantly decreased during colitis induced by $5 \%$ DSS ( $p=$ o.04). On the other hand, administration of $2.5 \%$ DSS in- 

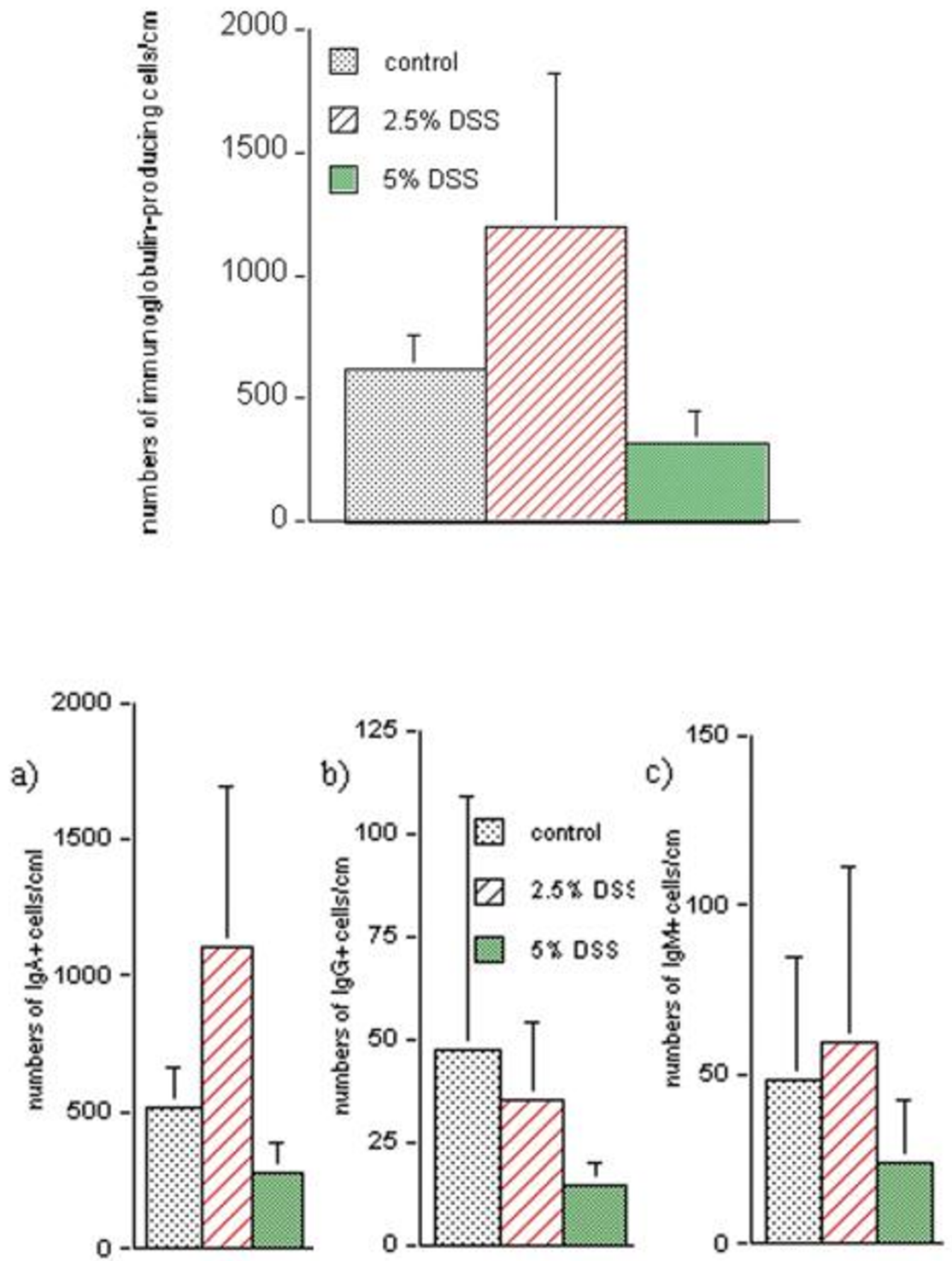

\section{Figure 6}

Numbers of immunoglobulin-producing cells/cm intestine (top of image), $\lg A+$ cells (a), $\lg G+$ cells (b) and $\lg M+$ cells (c) in healthy and inflamed colons at day 8 of $2.5 \%$ and $5 \%$ DSS ingestion. 


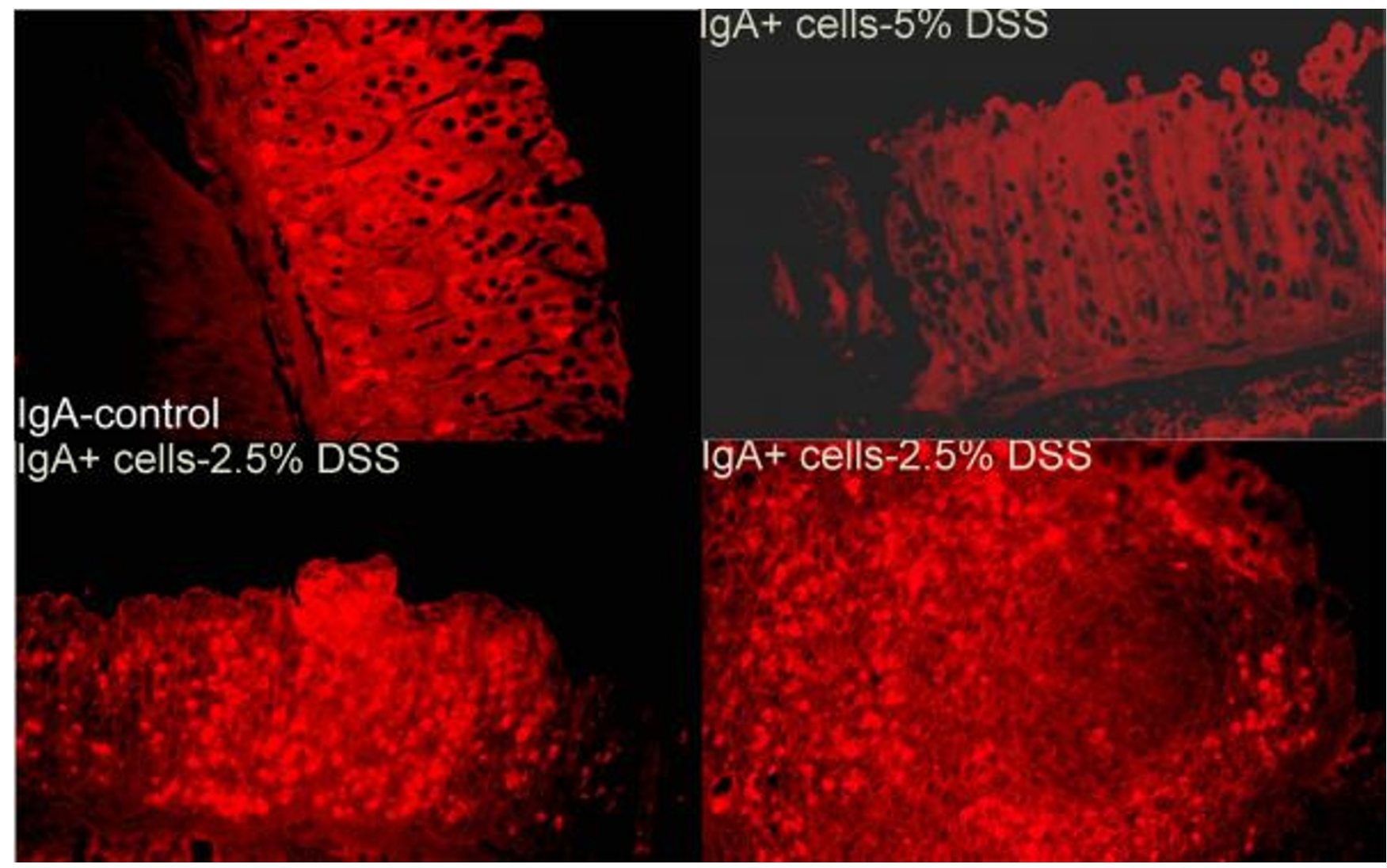

Figure 7

IgA-producing cells in healthy colonic tissue (control) and in inflamed colons at day 8 of $2.5 \%$ or $5 \%$ DSS ingestion. Numbers of IGA-producing cells were also increased at the outer layer of Payer's patches in colitis induced with $2.5 \%$ DSS (lower right). Original magnification $\times 20$.

duced an increase in $\operatorname{Ig} \mathrm{A}^{+}$cells in colonic lamina propria and on the periphery of Payer's patches (Figure 7).

Colonic mucosa of healthy mice contained much less IgG-producing cells. As seen with igA-producing cells, Ig- producing cells were found in lamina propria mucosae between the crypts and below the epithelial cells. Immunoglobulin $\mathrm{G}$ cell numbers in the colonic mucosa did not change significantly in inflamed colons of mice exposed to either concentration of DSS (Figure 8). There were few IgG-producing cells located on the periphery of Payer's patches. Numbers of IgM-containing cells was slightly increased in specimens from the $2.5 \%$ DSS-induced colitis and decreased in tissue from 5\% DSS-induced colitis (not up to a statistically significant level, $\mathrm{p}$ $=0.35$ ) (data not shown).

\section{Discussion}

It has been shown that macrophages are present in the lamina propria of the mouse gastrointestinal tract [26]. Our results confirmed these findings: $\mathrm{F} 4 / 8 \mathrm{O}^{+}$cells in the colon of healthy mice were found mainly in the subepi- thelial region and between crypts. Numbers of macrophages (as labeled with $\mathrm{F} 4 / 80$ ) increased during the course of the colitis indicating their involvement in the inflammatory response. Macrophages were distributed uniformly throughout the lamina propria and submucosa. Their numbers increased from day 6 of exposure to DSS. As shown in the result section, staining with ERMP 20 showed that a great number of macrophages in the inflammatory infiltrate are recently recruited peripheral blood monocytes.

Staining using antibody directed against DSS revealed its presence within macrophages thus confirming the results of others $[17,27]$ obtained with toluidine blue staining. The underlying hypothesis as proposed by Ohikusa et al. is that dextran sulphate inhibits macrophage phagocytosis of bacteria and that this permits bacterial invasion into the mucosa. They showed that the phagocytic index of spleen macrophages from mice exposed to DSS for 7 days is decreased. However, while dextran sulphate does inhibit phagocytic activity of macrophages for 


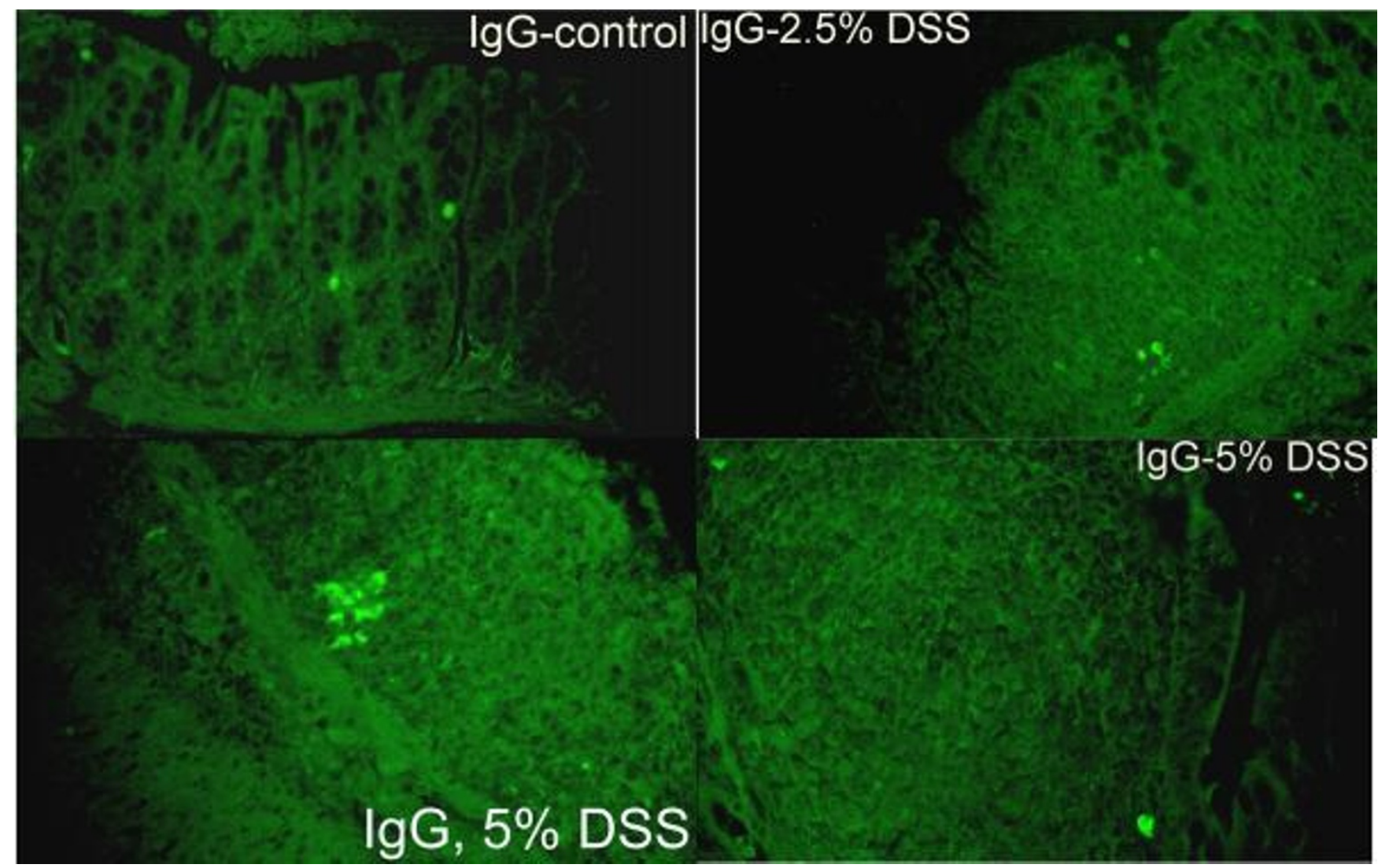

Figure 8

IgG-producing cells are scarce in healthy colonic tissue (control) and they are not more numerous on day 8 of the $2.5 \%$ or $5 \%$ DSS-induced colitis. Payer's patch contains few IgG positive cells located in the outer layer (lower right). Original magnification $\times 20$.

the first 72 hours of administration, after that, stimulation occurs [28].

MHC class II proteins play a central role in the presentation of antigens to $\mathrm{T}$ helper cells and their activation. It has been shown that expression of MHC class II antigen does not correlate directly with antigen presentation but bearing in mind the huge antigen load in the intestine, and given the observed epithelial expression of class II antigen in these experiments it can be speculated that antigen presentation and the subsequent immunological reactions do occur in colonic tissue. Whether the initial lesion occurs as a result of direct, nonspecific reactivity to DSS or not, specific immunological responses to DSS and the normal colonic flora may occur in the later stages of the disease.

An assessment of neutrophil infiltration was done by a conventional H\&E staining and in our material showed an increased numbers of neutrophils from day 6 of exposure to DSS. Specific immunohistochemical staining was not done in this study as it has been done by others. Their results showed an early infiltration with a small number of neutrophils from day 4 that occurred before arrival of any other inflammatory cell. Crypt abscesses filled with aggregated neutrophils were also seen (unpublished data, personal communication with Dr. Andrzej Wozniak), as they were demonstrated in this study with H\&E staining.

Assessment of $\mathrm{T}$ cell infiltration showed a decrease in numbers of CD8+ cells in the inflamed tissue while numbers of $\mathrm{CD}_{4}^{+}$cells were unchanged. Consequently the CD4/CD8 ratio was increased in specimens from day 8 of exposure to DSS ( $p=0.04)$. The significance of this finding is unclear. It is clear, however, that T cells do not contribute significantly to the inflammatory infiltrate in the acute phase of the disease.

Total numbers of immunoglobulin-containing cells were lower during the course of the acute colitis induced with $5 \%$ DSS, due to a decrease in numbers not only of $\mathrm{IgA}^{+}$ cells but also of IgG and IgM-containing cells. In contrast, numbers of immunoglobulin-containing cells in 
specimens from colons of mice in which colitis was induced with $2.5 \%$ DSS increased twofold. The increase was mainly in IgA-containing cells, while numbers of IgM-containing cells decreased significantly and numbers of IgG-containing cells did not change in the inflamed colon compared to healthy tissue. Comparison to the findings in human tissue from patients with IBD reveals some similarities, such as the increase of IgA-producing cells in patients with quiescent ulcerative colitis to the findings in DSS-colitis induced with 2.5\% DSS [16]. In contrast, the production of $\operatorname{IgA}$ in active ulcerative colitis lamina propria of the colon mononuclear cell cultures appeared to be significantly lower than that of both quiescent ulcerative colitis and controls in another study [29]. The proportion of IgA-containing cells was lower in ileal tissue from patients with IBD in one study [10], a difference that was confirmed in another study but was shown not to be significant [14]. Consequently, the $2.5 \%$ DSS-induced colitis could be used to study the behaviour of B cells in human quiescent colitis. The finding that IgG-containing cell numbers are unchanged is in contrast to the numerous studies which show a significant increase of IgG levels in human ulcerative colitis $[9,11,12]$. However, measuring the amount of secreted IgG, assessing IgG subclasses in the acute model and examining the changes in Ig-bearing cells in the chronic model may give results comparable to human IBD.

Dextran sulphate has a direct effect on B cells by inducing their proliferation and differentiation via receptors that are different from the specific Ig receptors; this mitogenic response depends on the degree of sulphur substitution of DSS [30]. However, the B cell population that is triggered by DSS consists mainly of relatively undifferentiated B cells, a population that may not be present in the colon. It may be that dextran sulphate sensitizes B cells to respond to LPS present in the lumen of the colon especially in the $2.5 \% \mathrm{DSS}$-induced colitis that is somewhat less severe. Experiments in vitro have shown that some B cell populations exposed to dextran sulphate show enhanced responsiveness to stimulation with LPS [31]. Also, simultaneous addition of dextran sulphate and LPS to spleen-derived B cell cultures leads to a synergistic, $\mathrm{T}$ cell-independent polyclonal response by directly activating B cells [32]. A study by Dieleman et al. [33] in which DSS-colitis was induced in SCID mice sheds light on the importance of different inflammatory cells in the induction of injury in this model. SCID mice lack functional $\mathrm{T}$ cells and B cells but have an intact innate immune system i.e. macrophages, granulocytes and NK cells are healthy under specific pathogen-free conditions [34]. Ingestion of DSS caused colitis in these mice therefore excluding the role of B and T lymphocytes in mediating the injury in this model. However, SCID mice were more susceptible to the disease indicating that ei- ther B or T cells may be protective in this colitis. The results of this study cannot completely exclude a possible role for the $\mathrm{T}$ cells as despite the lack of change in their numbers, their activation status may be affected by DSS. In this study, on the other hand, we have demonstrated changes of B cells population. Functional studies are needed to determine whether any of the two populations modifies the outcome of this colitis.

\section{Conclusion}

The inflammatory infiltrate in the first 8 days of the dextran sulphate sodium-induced colitis consists predominantly of macrophages, neutrophils and eosinophils. Macrophage numbers increase during the acute stage of the colitis due to an increase of newly recruited monocytes. By incubating macrophages with DSS and than using monoclonal anti-DSS antibody we were able to detect DSS within macrophages confirming that macrophages are able to phagocytose DSS. In addition, MHC Class II expression on macrophages increased in the inflamed tissue indicating that DSS may be processed and presented as an antigen.

Neutrophils are recruited very early into the lesion and were found within crypts forming crypt abscesses, in the lamina propria and at the basis of ulceration.

While numbers of $\mathrm{T}$ cells do not change, total numbers of immunoglobulin-containing cells were decreased in specimens from mice in which colitis was induced by ingestion of 5\% DSS and significantly increased in specimens from the $2.5 \%$ DSS-induced colitis. This was largely due to changes in IgA-producing cells that were the most affected at this stage of the inflammation.

\section{Competing interests}

\section{None declared.}

\section{References}

I. Nagashima R, Maeda K, Imai Y, Takahashi T: Lamina propria macrophages in the human gastrointestinal mucosa: their distribution, immunohistological phenotype, and function. J Histochem Cytochem 1996, 44:721-731

2. Hume DA, Allan W, Hogan PG, Doe WF: Immunohistochemical characterisation of macrophages in human liver and gastrointestinal tract: expression of CD4, HLA-DR, OKMI, and the mature macrophage marker 25F9 in normal and diseased tissue. J Leukoc Biol I 987, 42:474-484

3. Oshitani N, Campbell A, Kitano A, Kobayashi K, Jewell DP: In situ comparison of phenotypical and functional activity of infiltrating cells in ulcerative colitis mucosa. J Pathol 1996, I 78:9599

4. Rugtveit J, Brandtzaeg $\mathrm{P}$, Halstensen TS, Fausa $\mathrm{O}$, Scott H: Increased macrophage subset in inflammatory bowel disease: apparent recruitment from peripheral blood monocytes. Gut 1994, 35:669-674

5. Grimm MC, Pullman WE, Bennett GM, Sullivan PJ, Pavli P, Doe WF: Direct evidence of monocyte recruitment to inflammatory bowel disease mucosa. J Gastroenterol Hepatol 1995, 1 0:387-395

6. Britigan BE, Coffman TJ, Adelberg DR, Cohen MS: Mononuclear phagocytes have the potential for sustained hydroxyl radical production. Use of spin-trapping techniques to investigate 
mononuclear phagocyte free radical production. I Exp Med 1988, 168:2367-2372

7. Hirata I, Berrebi G, Austin LL, Keren DF, Dobbins WO 3rd: Immunohistological characterization of intraepithelial and lamina propria lymphocytes in control ileum and colon and in inflammatory bowel disease. Dig Dis Sci 1986, 31:593-603

8. Senju M, Wu KC, Mahida YR, Jewell DP: Coexpression of CD4 and CD8 on peripheral blood T cells and lamina propria $T$ cells in inflammatory bowel disease by two colour immunofluorescence and flow cytometric analysis. Gut 1991, 32:918-922

9. Brandtzaeg P, Baklien K, Fausa O, Hoel PS: Immunohistochemical characterization of local immunoglobulin formation in ulcerative colitis. Gastroenterology 1974, 66: I I23-1 I 36

10. Wu KC, Mahida YR, Priddle JD, Jewell DP: Immunoglobulin production by isolated intestinal mononuclear cells from patients with ulcerative colitis and Crohn's disease. Clin Exp Immunol 1989, 78:37-4I

II. Scott MG, Nahm MH, Macke K, Nash GS, Bertovich MJ, MacDermott RP: Spontaneous secretion of IgG subclasses by intestinal mononuclear cells: differences between ulcerative colitis, Crohn's disease, and controls. Clin Exp Immunol 1986, 66:209-2 I5

12. MacDermott RP, Nash GS, Auer IO, Shlien R, Lewis BS, Madassery J, $\mathrm{Nahm} \mathrm{MH}$ : Alterations in serum immunoglobulin G subclasses in patients with ulcerative colitis and Crohn's disease. Gastroenterology 1989, 96:764-768

13. Gryboski JD, Buie T: Immunoglobulin studies in children with inflammatory bowel disease. Ann Allergy 1994, 72:525-527

14. Cicalese L, Duerr RH, Nalesnik MA, Heeckt PF, Lee KK, Schraut WH: Decreased mucosal IgA levels in ileum of patients with chronic ulcerative colitis. Dig Dis Sci 1995, 40:805-8I I

15. Philipsen EK, Bondesen S, Andersen J, Larsen S: Serum immunoglobulin $\mathbf{G}$ subclasses in patients with ulcerative colitis and Crohn's disease of different disease activities. Scand J Gastroenterol 1995, 30:50-53

16. Badr-el-Din S, Trejdosiewicz LK, Heatley RV, Losowsky MS: Local immunity in ulcerative colitis: evidence for defective secretory IgA production. Gut 1988, 29:1070-1075

17. Okayasu I, Hatakeyama S, Yamada M, Ohkusa T, Inagaki Y, Nakaya R: A novel method in the induction of reliable experimental acute and chronic ulcerative colitis in mice. Gastroenterology 1990, 98:694-702

18. Stevceva L, Pavli P, Buffinton G, Wozniak A, Doe WF: Dextran sodium sulphate-induced colitis activity varies with mouse strain but develops in lipopolysaccharide-unresponsive mice. J Gastroenterol Hepatol 1999, 14:54-60

19. Kongtawelert P, Ghosh P: A monoclonal antibody that recognizes 2,3-, 2,6-, and 4,6-disulphate ester ring substitution in pyranose-containing polysaccharides. Its production, characterization and application for the quantitation of pentosan polysulphate, dextran sulphate, glycosaminoglycan polysulphate and chondroitin sulphate E. J Immunol Methods 1990, 1 26:39-49

20. Sainte-Marie G: A paraffin embeding technique for studies employing immunofluorescence. J Histochem Cytochem 1962, 10:250-256

21. Sheldrake RF, Husband AJ, Watson DL, Cripps AW: Selective transport of serum-derived IgA into mucosal secretions. J Immunol 1984, 132:363-368

22. Husband AJ, Gowans JL: The origin and antigen-dependent distribution of IgA-containing cells in the intestine. J Exp Med 1978, I 48:1146-1160

23. Leenen PJ, Melis M, Slieker WA, Van Ewijk W: Murine macrophage precursor characterization. II. Monoclonal antibodies against macrophage precursor antigens. Eur J Immunol 1990, 20:27-34

24. Natsui M, Kawasaki K, Takizawa H, Hayashi SI, Matsuda $Y$, Sugimura K, Seki K, Narisawa R, Sendo F, Asakura H: Selective depletion of neutrophils by a monoclonal antibody, RP-3, suppresses dextran sulphate sodium-induced colitis in rats. I Gastroenterol Hepatol 1997, I 2:80I-808

25. Stevceva L, Pavli P, Husband A, Matthaei KI, Young IG, Doe WF: Eosinophilia is attenuated in experimental colitis induced in IL-5 deficient mice. Genes Immun 2000, I:2 13-2 I8

26. Hume DA, Halpin D, Charlton H, Gordon S: The mononuclear phagocyte system of the mouse defined by immunohisto- chemical localization of antigen F4/80: macrophages of endocrine organs. Proc Natl Acad Sci U S A 1984, 81:4174-4177

27. Ohkusa T, Okayasu I, Tokoi S, Araki A, Ozaki Y: Changes in bacterial phagocytosis of macrophages in experimental ulcerative colitis. Digestion 1995, 56:159-164

28. Bloksma N, de Reuver MJ, Willers JM: Influence on macrophage functions as a possible basis of immunomodification by polyanions. Ann Immunol (Paris) I980, I 3 I D:255-265

29. Squarcia $O$, Fais S, Boirivant M, Di Paolo MC, Marcheggiano A, lannoni C, Paoluzi P, Pallone F: Phenotypes and spontaneous immunoglobulin production in mononuclear cells suspensions isolated from colonic biopsies of patients with mild active and quiescent ulcerative colitis. Gastroenterol Clin Biol 1991, I 5:194198

30. Coutinho A, Moller G, Richter W: Molecular basis of B-cell activation. I. Mitogenicity of native and substituted dextrans. Scand J Immunol I974, 3:32 I-328

31. Coutinho A, Gronowicz E, Sultzer BM: Genetic control of B-cell responses. I. Selective unresponsiveness to lipopolysaccharide. Scand I Immunol 1975, 4: I39-I 43

32. Bergstedt-Lindqvist S, Fernandez C, Severinson E: A synergistic polyclonal response to dextran sulphate and lipopolysaccharide: immunoglobulin secretion and cell requirements. Scand J Immunol I 98I, I 5:439-448

33. Dieleman LA, Ridwan BU, Tennyson GS, Beagley KW, Bucy RP, Elson CO: Dextran sulfate sodium-induced colitis occurs in severe combined immunodeficient mice. Gastroenterology 1994, 107:1643-1652

34. Bosma MJ, Carroll AM: The SCID mouse mutant: definition, characterization, and potential uses. Annu Rev Immunol I99I, 9:323-350

Publish with BioMed Central and every scientist can read your work free of charge

"BioMedcentral will be the most significant development for disseminating the results of biomedical research in our lifetime."

$$
\text { Paul Nurse, Director-General, Imperial Cancer Research Fund }
$$

Publish with BMC and your research papers will be:

- available free of charge to the entire biomedical community

- peer reviewed and published immediately upon acceptance

- cited in PubMed and archived on PubMed Central

- yours - you keep the copyright 